\title{
RESENHA
}

\section{Os índios e a pesquisa dos juristas tradicionais}

ARAUJO JUNIOR, Julio José. Direitos territoriais indígenas: uma interpretação intercultural. Rio de Janeiro: Processo, 389 p., 2018.

\section{João Vitor de Freitas Moreira ${ }^{1}$}

${ }^{1}$ Universidade Federal de Minas Gerais, Belo Horizonte, Minas Gerais, Brasil. E-mail: joaovitorfmoreira@gmail.com. ORCID: https://orcid.org/0000-0002-8508-7699.

Resenha recebida em 29/06/2020 e aceita em 21/11/2020.

\section{$(\mathrm{cc}) \mathrm{EY}$}

This work is licensed under a Creative Commons Attribution 4.0 International License. 
ão é comum encontrar na vasta literatura jurídica uma obra que se dedique exclusivamente a pesquisar categorias do direito oficial em relação aos povos indígenas, tal como fez Julio José Araújo Junior em "Direitos territoriais indígenas: uma interpretação intercultural". Isso, contudo, não significa dizer que inexistam trabalhos dedicados à discutir e criticar o direito oficial quando se relaciona a "questão" indígena. Nesse contexto, o livro em questão chega ao cenário acadêmico para fazer companhia a autores de peso, como Manuela Carneiro da Cunha (1987; 1992), Mendes Jr. (1912) e Carlos Frederico Marés de Souza Filho (2018 [1998]). Notadamente, não nos parece que este texto tenha menor importância, até porque foi um finalista do Prêmio Jabuti em Direito de 2019.

O autor, atualmente, ocupa um cargo no Ministério Público Federal e acumula uma história de atuação nas mais variadas carreiras jurídicas. O que nos interessa, contudo, é que este livro é produto de uma dissertação de mestrado defendida em 2018 na Universidade do Estado do Rio de Janeiro, sob a orientação do Prof. Dr. Daniel Sarmento. Trata-se, assim, de uma pesquisa científica em direito que tem como foco essencial os direitos territoriais indígenas lidos sob uma perspectiva intercultural. É provável que o interesse sobre essa temática, deixada à margem curricular das Faculdades de Direito, decorra da atuação do autor na Procuradoria da República no Amazonas, sobretudo devido ao episódio ocorrido em Humaitá-AM, relatado na introdução do texto.

No campo acadêmico, o conhecimento de Julio José Araujo Junior aparece em uma importante publicação coordenada pela Manuela Carneiro da Cunha e Samuel Barbosa (2018) após o seminário sobre Direitos dos Povos Indígenas em Disputa, ocorrido em 2015 na FD/USP-SP. Se um prelúdio ou não, o texto daquela publicação traz muitos assuntos a serem tratados na dissertação de mestrado, especificamente o enfrentamento de inúmeros teóricos contemporâneos que dificilmente se convergiriam não fosse 0 impressionante poder de síntese do autor. Inclusive, essa será uma marca ao longo de todo este trabalho.

A obra em questão se divide em cinco capítulos, sendo difícil identificar uma hipótese adequadamente delimitada nos termos de uma metodologia de pesquisa científica, embora o recorte da análise esteja claro desde o título. O que experenciamos ao longo da leitura são inúmeros objetivos específicos para alcançar a proposta teórica que o autor se colocou: apresentar uma interpretação intercultural. Para tanto, algumas premissas são estabilizadas como o fato de que “[...] o tratamento da matéria indígena 
carece de um enfoque paritário" (p. 5), ou que "[a] percepção que vigora acerca dos povos indígenas remete a ideias como primitivismo e infantilidade." (p. 3), donde é necessário "[...] descolonizar o estudo das propriedades [...]" (p. 7) para se retirar a posição marcada pela vulnerabilidade ainda persistente no cenário dos índios nesta terra (p. 3). Todas essas premissas, e muitas outras ao longo do texto, são verdadeiras e o autor não faz muito ao alocá-las no campo das suas análises, haja vista o paternalismo complacente do tratamento Estado-indígena que vigora nas ficções jurídicas. $O$ destaque está justamente na tentativa de apresentar a proposta hermenêutica da interculturalidade em oposição à multiculturalidade como linguagem de tratamento dos direitos territoriais. Porém, o autor, é importante frisar desde logo, não se preocupa com a territorialidade ou territórios sociais (LITTLE, 2005) ou sobre as mais variadas formas que os povos nativos compreendem e produzem relações com o que nomeamos de "terra".

No primeiro capítulo, denominado "Os caminhos do multiculturalismo e seus limites", nosso autor inicia de forma muito interessante a configuração do seu diagnóstico sobre o multiculturalismo com Davi Kopenawa e a celebrada obra "A queda do céu: palavras de um xamã yanomami" (2015), mas tão logo os ensinamentos de Omama são deixados de lado e a discussão de filosofia política vem à tona. Os autores aqui começam a pulular e é onde encontramos o grande potencial do pesquisador: sua capacidade de relacionar variadas matrizes teóricas com um objetivo comum. Começando nos liberais igualitários, passando pelos comunitaristas e pelas teorias feministas, o autor desemboca no binômio bastante comum na filosofia política da primeira metade do século: reconhecimento vs. redistribuição. Figuras comuns da Immanent kritik e da teoria crítica são colocados em debate, cujo denominador comum está na construção do paradigma multicultural que eles, de alguma forma ou de outra, parecem contribuir. Segundo nosso autor, "o que se buscou foi mostrar como o multiculturalismo liberal, ao discutir a construção de modelos que permitam a convivência entre culturas, deixa clara a posição proeminente de certos valores e um certo desinteresse pelas cosmovisões de outros grupos" (p. 52). Por fim, recorre à hermenêutica diatópica de Raimon Panikkar ofertada na leitura de Boaventura de Sousa Santos (2003) e apresenta uma visão sobre a incompletude das culturas e a necessidade de se criar mecanismos de diálogos. Curioso é ver como esse raciocínio, que está disponível criticamente na literatura desde Rita Laura Segato (2006), é assimilado sem se considerar as dimensões simbólicas inscritas (CARDOSO DE OLIVEIRA, 2010) nas formas jurídicas capazes de demonstrar que há - 
mesmo diante de situações interessantes e de possíveis diálogos - uma dimensão das relações em conflito que não é adequadamente traduzida em linguagem jurídica (CARDOSO DE OLIVEIRA, 2011). Talvez, seja necessário refletir sobre as assimetrias intrínsecas nas estruturas culturais dominantes, onde falar em diálogo não é possível sem a contramão do enfrentamento social que aponte a equivocação da arrogância na razão ocidental. Como diria Kopenawa, que volta somente ao final deste capítulo: "não há dúvida de que eles [os Brancos] têm muitas antenas e rádios em suas cidades, mas estes servem apenas para escutar a si mesmos" (KOPENAWA; ALBERT, 2015, p. 461).

No segundo capítulo, a interculturalidade como projeto hermenêutico será abordada com uma interessante densidade teórica. Os recursos utilizados agora são da ordem dos estudos pós-coloniais, tendo como figuras centrais Aníbal Quijano, Edward Said, Gayatri Spivak, Catherine Walsh entre outros. O objetivo é enfrentar a "ferida colonial", ou as outras formas de designação desse gênero que abundam nesse capítulo. O autor apresenta no item 2.3 uma inflexão analítica ao colocar que o multiculturalismo, à luz da crítica pós-colonial, "[...] apesar de conter instrumentos e propostas que valorizem o direito à diferença [...] não atendem às demandas dos povos subalternos que vivem a colonialidade do poder, especialmente grupos étnicos" (p. 78). A mudança de vocabulário utilizado para designar os povos nativos é evidente, assim como a contrafilosofia de Kopenawa deixa de fazer parte do esquema teórico do autor na construção da crítica ao multiculturalismo. Entre outros motivos, "[o] multiculturalismo peca também por não conferir o devido peso à historicidade e à profundidade da ferida colonial" (p. 81), não percebendo que a "inferiorização dos grupos é constitutiva da própria modernidade" (p. 82). Em sequência, um importante autor aparece em uma colocação apressada, quase que citado por obrigação, e se trata de Eduardo Viveiros de Castro. Ao trazer para a discussão o conceito de perspectivismo ameríndio (1996), o leitor mais atento à etnologia americanista esperaria uma exploração da ontologia multinaturalista que a tradição animista tem retomado no contexto contemporâneo (COSTA; FAUSTO, 2010) e que tem dado cabo à afirmação de uma virada ontológica na Antropologia (HOLBRAAD; PEDERSEN 2018). Porém, a argumentação preferiu filósofos pós-coloniais (e suas variações sintetizadas nos termos descolonial e decolonial) a um interessante debate aberto por Idelber Avelar (2013) sobre as reverberações do perspectivismo no campo dos direitos humanos. Nesse contexto, sugeriria aqui uma importante lição de Philippe Descola e que 
jamais deveria ter sido esquecida: precisamos utilizar as armas dos filósofos para caçar em territórios que eles não frequentam (2006, p. 420).

A opção intercultural, segundo o autor, permite a construção de identidades em contraste com outras (p. 84), possibilitando que os indígenas sejam sujeitos ativos e passivos das transformações políticas e culturais em suas sociedades (p. 84). A interculturalidade, assim, é muito mais que uma alternativa terminológica: "[t]rata-se de uma proposta de aprendizado recíproco que defende, no campo jurídico, a criação e a interpretação de normas de uma maneira que tome em consideração as distintas perspectivas e espaços" (p. 88). Dito isso, é de se esperar uma aplicação a termo, o que é satisfeito a partir da exemplificação de uma construção intercultural desde o Sul, especificamente a partir do constitucionalismo latino-americano. Julio José apresenta inúmeras normas constitucionais de outros contextos da América do Sul (Equador e Bolívia) para evidenciar uma interculturalidade que está em texto normativo e em construção. Essa exemplificação chama atenção pois deixa de lado uma importante publicação organizada pela Prof. Alcida Ramos (2007) que traz autores indígenas discutindo suas constituições, um texto essencial quando queremos ter em nosso horizonte a interculturalidade no debate do constitucionalismo latino-americano. Em segundo momento, é somente na página 119 que o autor retomará o tema das terras indígenas para introduzir o Capítulo 3: "Legislação e interpretação: a visão colonial e colonialista sobre os povos indígenas", deixando de lado algumas pontas que abriu no capítulo em prol de uma retórica embebida em boa revisão de literatura.

Neste terceiro capítulo o texto muda de tom. $\mathrm{O}$ autor sente a necessidade de fazer um retorno à legislação do Brasil Colônia sobre o tratamento dos indígenas na legislação, progredindo em uma linha reta ao pinçar normas e legislação referente às terras indígenas durante o Império e a República. Embora esse estilo de produção já esteja disponível na literatura, o autor nos convida a fazer uma releitura no estilo "breve histórico" dos juristas tradicionais. Aos historiadores do direito, este capítulo é estranho, pois não há uso de fontes, nem muitos menos um recorte detido do período analisado. Em outras palavras, a deficiência metodológica vai se revelando cada vez mais e, nesse momento, experenciamos uma revisão de literatura muito importante, mas que não é devidamente manuseada. Tratar do regime tutelar, dos problemas relacionados às terras indígenas na legislação do Império, das teorias do Indigenato e do Fato Indígena, da problemática da titularidade de terras indígenas, dos problemas do tokenismo cotidiano 
entre outros assuntos é extremamente pertinente, porém, o rigor ao se fazer tal produção é necessário para que se possa adjetivá-la como científica. Não é percorrer “[...] de forma sumária, séculos da história do Brasil [...]” (p. 197) que se alcança rigor científico. Isso é o que diferencia essa revisão de literatura apresentada pelo nosso autor de trabalhos como o de Carolina Ribeiro Santana (2011) e, especialmente, o projeto de pesquisa levado pela Prof. Camila Dias (Unicamp) sobre a Constituinte e os direitos indígenas. Por fim, o item 3.6 se propõe a discutir o novo paradigma fundado pela Constituição de 1988, uma vez que "revisitar o momento da elaboração da lei fundamental brasileira é mais do que um exercício de interpretação histórica, pois não somente permite compreender os interesses envolvidos, os consensos, os avanços e os retrocessos na nossa trajetória, mas também as disputas atuais [...]" (p. 177). Essa proposta constituiria um objeto de pesquisa capaz de ocupar inúmeras páginas, mas é foco somente de um subitem que ocupa 19 páginas. Porém, lembremo-nos do objetivo do autor: apresentar uma interpretação intercultural. Esse objetivo volta superficialmente no final deste capítulo para concluir que o texto constitucional de 1988 atende ao "[...] anseio liberal multicultural de assegurar proteção externa aos direitos de grupos [...]" (p. 201), mas as cosmovisões indígenas não entraram no texto constitucional, sendo o diálogo desenvolvido menos profícuo se comparado aos textos constitucionais de países vizinhos. A Constituição de 1988 seria, dessa forma, um projeto com caráter transformador ainda por florescer ( $p$. 202).

No capítulo 4, nomeado "As terras indígenas após a Constituição de 1988", o autor nos apresentará uma análise sobre as decisões do Supremo Tribunal Federal no que concerne aos direitos territoriais no pós-1988, tomando como paradigma o julgamento da Pet. 3388/RR, conhecido como Caso Raposa Serra do Sol. Inicia sua exposição colocando o regime jurídico das terras indígenas na Constituição, problematizando os termos utilizados na construção do art. 231 tal como "terra tradicional", cujo significado "não remete a uma permanência física em um local em determinado momento histórico, que exija o recuo temporal a uma época passada" (p. 215), mas guarda relação com a maneira como os indígenas se relacionam com a terra. Esse mesmo tipo de técnica, que nos lembra um parecer jurídico, vai sendo aplicado ao corpo do artigo constitucional que se trata, segundo nosso autor, de uma contextualização geral do debate doutrinário. Em sequência, apresenta uma série de comentários sobre as decisões do Supremo Tribunal Federal partindo do caso dos Borum do médio rio Doce (Krenak) e outras jurisprudências 
do tribunal referentes à terra indígena que ele prefere chamar de "precedentes". Ao chegar no conflito judicializado em relação à demarcação da Raposa Serra do Sol, há uma precisão do autor ao dirigir suas críticas às condicionantes anexadas ao julgamento. As críticas a essa jurisprudência se desdobram nas contradições que a decisão colegiada resguarda com a Constituição, com o pensamento científico sobre a territorialidade ameríndia e com outros casos enfrentados pelo Supremo. Um caso paradigmático que tem sido utilizado para justificar o retrocesso democrático experienciado pelo Estado brasileiro com o Parecer 001/2017, da Advocacia Geral da União. Em outras palavras, aquela mirabolante decisão judicial transformou o chamado "marco temporal" em política de Estado, hoje desafiado no RE 1017365.

De qualquer forma, neste capítulo o autor promove um diagnóstico interessante sobre as teorias adotadas pelos STF acerca da demarcação territorial, a saber: teoria do Fato Indígena e o Indigenato. Essas ideias, debatidas no capítulo anterior, são entendidas como lastros de fundamentação à decisão judicial da seguinte forma: a primeira, Fato Indígena, consiste na ideia de que o direito territorial prescrito na constituição como "terra tradicionalmente ocupada" presumiria a existência dos indígenas no exato local que reivindicam na data do dia 05 de outubro de 1988. Por outro lado, o Indigenato nos leva a reconhecer a precedência do direito originário que os povos indígenas têm em relação ao território, permitindo identificar as assimetrias existentes nas relações de violência e poder que permeiam a questão territorial no Brasil, especialmente no que concerne à constante expulsão de indígenas dos locais que habitam devido à expansão agrícola. O Supremo, embora tenha reconhecido em outros momentos a teoria do Indigenato adotada na Constituição de 1988, tem promovido a aplicação do projeto perdedor na Constituinte, reavivando formas de pensar superadas no campo acadêmico e doutrinário. Uma pergunta interessante, infelizmente não realizada, seria: quais são os motivos que permeiam essa mudança de postura pelo Supremo Tribunal Federal? Novamente, um campo novo para análise que clama por pesquisas empíricas.

O último capítulo é nomeado "Por uma proposta intercultural de interpretação dos direitos territoriais indígenas". Nesse ponto, o livro tentará promover um conexão entre a interculturalidade e o direito à terra e, para tanto, propõe três diretrizes: i) todas as normas que tratam do direito de propriedade devem estar sujeitas a uma leitura que aborde os direitos territoriais indígenas, pois a Constituição Federal abarcaria variados sentidos de propriedade; ii) "a garantia dos direitos territoriais deve ser encarada como 
um mecanismo de efetivação intercultural do princípio da igualdade, mediante uma combinação intensa de ferramentas de reconhecimento e redistribuição" (p. 274); iii) é imprescindível "conferir visibilidade ao protagonismo indígena na condução de processos políticos que contribuam para a ressignificação dos conceitos existentes" (p. 275). Essas três afirmações serão, em alguma medida, desenvolvidas ao longo do capítulo a começar pela diversificação da propriedade, exemplificando não apenas a partir das normas oficiais do direito brasileiro, mas também através de casos retirados do Sistema Interamericano de Direitos Humanos e do Sistema Africano de Proteção os Direitos Humanos. O interessante deste capítulo é a forma como o autor se esforça para dar conteúdo novo aos velhos conceitos, especificamente ao direito de propriedade que ganha uma vertente pluralizada ("multiplicidade de propriedades"), assim como deve estar aberto à interpretação que inclua a terra indígena como uma propriedade, sendo esse o anseio constitucional revalidado pelo Sistema Interamericano de Direitos Humanos. Estaríamos, portanto, diante de um direito "fundamental territorial indígena prima facie que decorre da perspectiva indígena. No caso, a propriedade é definida pela valorização de saberes e sentidos em torno do território, que incluem a filosofia e a antropologia indígenas, as memórias orais [...]" (p.307) entre outros fatores que caracterizam os povos nativos dessa terra. Por ser uma "norma-regra" fundamental, há uma precedência do direito territorial indígena sobre a propriedade de particular e o autor irá promover um raciocínio lógico em defesa dessa assertiva. Do ponto de vista do protagonismo indígena não encontramos uma análise sobre a forma como os povos indígenas agenciaram as estruturas oficiais, mas trata-se de um momento em que o autor se dedica a apresentar mandamentos deônticos e lamentações sobre a perversidade das formas oficiais que, seguramente, aplicam-se a pessoas de diversos recortes sociais. 0 leitor fica à espera de um objeto a ser analisado, de uma questão que poderia exemplificar a mobilização indígena nacional, mas é agraciado com construções que abundam no uso de verbos que expressam um conselho ou um parecer de como as coisas devem ser feitas, tais como "a manifestação indígena deve ser obrigatória [...]" (p. 348) ou "a justiça cognitiva preconiza que as explicações devem valorizar as memórias e as interpretações [...]" (p. 349).

Ao final, a conclusão do trabalho apresenta 15 pontos que são justamente os objetivos específicos concretizados e que retomam pontos dos 5 capítulos anteriores, passando pelas deficiências do multiculturalismo até chegar na interpretação cultural 
como cânone hermenêutico a ser aplicado (e construído) em relação à legislação atinente aos direitos indígenas, notadamente o direito à terra.

Dito isso, ao observarmos o livro em sua totalidade notamos que o autor enfrenta seu objetivo inicial a partir da verificação de muitos dos seus objetivos específicos que tecem o caminho pelo qual ele percorre. Entretanto, cada capítulo parece ser um "parecer" sobre um tema diferente e a ausência de um método de pesquisa deixa o leitor sem muitos mecanismos para apreciar a leitura como um trabalho científico. É importante dizer, se os ensinamentos de Miracy Gustin e Marcos Vinício Chein Feres ainda são válidos, que mesmo em pesquisas de caráter "teórico" há de se ter uma amostragem, uma hipótese, perguntas de pesquisa e um método. Tomemos, por exemplo, um autor muito debatido na FD-UERJ que é Axel Honneth. Ao nos debruçarmos sobre seus estudos sobre a liberdade (HONNETH, 2015), encontramos logo na introdução uma explicação do método da reconstrução normativa. Em outra publicação (HONNETH, 2018), o mesmo autor denomina seu primeiro capítulo da seguinte maneira: "Ideengeschichte und Begriffsgeschichte: Methodische Vorüberlegungen". Ou seja, há considerações metodológicas preliminares que permitem ao leitor entender a reconstrução da ideia do reconhecimento como uma ideia europeia. A ausência de método de pesquisa é o principal problema do texto.

Por outro lado, os méritos dessa publicação começam exatamente no seu afastamento de um mainstream de pesquisas jurídicas que é, sem sombra de dúvidas, importante. É perceptível a dedicação na escrita e no tratamento do direito territorial indígena e o esforço para criar um diálogo com outras áreas, principalmente a Antropologia. Embora os juristas tenham maior feitio por produções ensaísticas, é importante chamar atenção para uma mudança em curso no cenário brasileiro e que a Direito \& Práxis têm sido espaço de veiculação. A demanda indígena, inclusive, já foi debatida por interessantes artigos aqui publicados e que adotam uma vertente da pesquisa empírica. Desse modo, o tema que o autor Julio José Araujo Junior traz é extremamente relevante e sua consciência enquanto ator jurídico nesse campo é ainda mais importante, pois encontrar um sujeito que desloca tamanho esforço para tratar de tal matéria é louvável e esperançoso.

Certamente, ainda vamos encontrar novas e melhores publicações sobre as terras indígenas por esse autor e, quem sabe, em uma vertente que traga não um panorama geral, mas uma questão local enraizada em uma boa análise 
metodologicamente estruturada. Há muito potencial nas entrelinhas da argumentação do livro. Entretanto, é necessário discordarmos do prefácio que apresenta a obra como “[...] o que se escreveu de melhor no Brasil sobre os direitos dos povos indígenas", pois isso não é somente injusto, como mostra a deficiência refratária do olhar tradicional dos juristas para o campo da interdisciplinaridade. Para finalizar, Roy Wagner (1981, p. 11) faz uma importante afirmação n'A invenção da cultura que me permito uma paráfrase adequada ao campo jurídico: [Um Direito] que nunca deixa os limites de suas próprias convenções, que desdenha investir sua imaginação em um mundo de experiência, deverá sempre permanecer mais uma ideologia do que ciência.

Referências bibliográficas

AVELAR, Idelber. Amerindian Perspectivism and Non-Human Rights. Ciencia y Cultura, n. 31,2013 , p. 255-275

ARAUJO JUNIOR, Julio José. A constituição de 1988 e os direitos indígenas: uma prática assimilacionista? In: CARNEIRO DA CUNHA, Manuela; BARBOSA, Samuel (Org.). Direitos dos povos indígenas em disputa. São Paulo: Editora Unesp, 2018.

CARDOSO DE OLIVEIRA, Luís. R. A dimensão simbólica dos direitos e a análise de conflitos. Revista de antropologia, v. 53, n. 2, p. 451-473, 2010.

CARDOSO DE OLIVEIRA, Luís R. Direito legal e insulto moral: dilemas da cidadania no Brasil, Quebec e EUA. 2 ed. Rio de Janeiro: Garamond, 2011.

CARNEIRO DA CUNHA, Manuela. Os direitos do índio: ensaios e documentos. São Paulo:1987.

COSTA, Luiz; FASUTO, Carlos. The returno $f$ the animists: recent studies of Amazonian Ontologies. Religion and Society: advances in Research, v. 1, 2010, p. 89-109.

DESCOLA, Philippe. As lanças do crepúsculo: relações jivaro na Alta Amazônia. São Paulo: Cosac Naify, 2006.

HOLBRAAD, Martin; PEDERSEN, Morten Axel. The ontological turn: an anthropological exposition. New York (US): Cambridge University Press, 2018.

HONNETH, Axel. O direito da liberdade. São Paulo: Martins Fontes, 2015.

HONNETH, Axel. Anerkennung: eine europäische Ideengeschichte. Berlin: Suhrkamp, 2018. 
KOPENAWA, Davi; ALBERT, Bruce. A queda do céu: palavras de um xamã yanomami. São Paulo: Companhia das Letras, 2015.

LITTLE, Paul. E. Territórios sociais e povos tradicionais no Brasil: por uma antropologia da territorialidade. Anuário Antropológico, v. 2003, 2005, p. 251-290.

MENDES JUNIOR, João. Os indígenas do Brasil, seus direitos individuais e políticos. São Paulo: Typ. Hennies Irmãos, 1912.

MARÉS DE SOUZA FILHO, Carlos Frederico. O renascer dos povos indígenas para o direito. 9 ed. Curitiba: Juruá, 2018.

SANTANA, Carolina Ribeiro. Pacificando o Direito: desconstrução, perspectivismo e justiça no direito indigenista. 2011. Dissertação (Mestrado em Direito) - Pontifícia Universidade Católica do Rio de Janeiro, Rio de Janeiro, 2011.

SOUSA SANTOS, Boaventura. Por uma concepção multicultural de direitos humanos. In: SOUSA SANTOS, Boaventura (Org.). Reconhecer para libertar: os caminhos do cosmopolitismo multicultural. Rio de Janeiro: Civilização Brasileira, 2003, p. 427-461.

SEGATO, Rita Laura. Antropologia e Direitos Humanos: alteridade e ética no movimento de expansão e consolidação dos direitos universais. Mana, v. 12, n.1, 2006, p. 207-236.

VIVEIROS DE CASTRO, Eduardo. Os pronomes cosmológicos e o perspectivismo ameríndio.

Mana, v. 2, $\quad$ n. 2, $1996 . \quad$ Disponível em: http://www.scielo.br/scielo.php?script=sci_arttext\&pid=S0104-93131996000200005. Acesso em 20 jun. 2020.

WAGNER, Roy. The invention of culture. Chicago: The University of Chicago Press, 1981.

Sobre o autor

\section{João Vitor Moreira}

Doutorando e mestre em Direito pela UFMG. Desenvolve pesquisas no campo da Antropologia do Direito, com ênfase nas seguintes áreas: direito indígena, etnologia americanista e conflitos socioambientais. E-mail: joaovitorfmoreira@gmail.com

O autor é o único responsável pela redação da resenha. 